\title{
APPLICATION OF NEURAL NETWORK IN DROUGHT FORECASTING; AN INTENSE LITERATURE REVIEW
}

\author{
Akhilesh Kumar Yadu \\ Department of Computer Science, NMDC DAV Polytechnic College, \\ Geedam - Dantewada, Chhattisgarh, India \\ Gyanesh Shrivastava \\ School of Information Technology, MATS University, Raipur, Chhattisgarh, India
}

\begin{abstract}
India is the agrarian country. The overall economy of our country is based on agriculture. Although the methods of cultivation are traditional and not hi-tech thus more over $75 \%$ of our farmers are dependent on monsoon. Prediction of actual monsoon is a challenge for meteorological scientists. Since the climatic data time series shows highly non-linear and chaotic behavior thus its forecast is still an enigma. Thus, forecasting of climate phenomenon is a challenging issue for the researchers round the globe. However, it is a prime necessity to forecast climatic changes such as Rainfall (daily rainfall, monthly rainfall, heavy rainfall etc.), Flood, Drought, minimum and maximum Temperature, River flow etc. To recognize applications of Artificial Neural Network (ANNs) in weather forecasting, especially in drought forecasting a comprehensive literature review from 2000 to 2017 is done and presented in this paper. In the study, more over 90 contributions have been surveyed and it has been observed that the architecture of ANN such as BPN, RBFN, MLP, ANFIS, ARIMA etc. are found best to forecast chaotic behavior and have efficient enough to forecast drought as well as other weather phenomenon over broader or smaller homogeneous region.
\end{abstract}

Keywords: Forecasting, Drought, Climatology, Neural Network.

Cite this Article: Akhilesh Kumar Yadu, Gyanesh Shrivastava, Application of Neural Network in Drought Forecasting; An Intense Literature Review, International Journal of Computer Engineering and Technology, 10(2), 2019, pp. 180-195.

http://iaeme.com/Home/issue/IJCET?Volume=10\&Issue=2

\section{INTRODUCTION}

India is an agrarian country and agriculture is the backbone of Indian economy. However harvesting technology is not so much advanced in India likewise other countries. Thus, our farmers are still dependent on climate for crop cultivation. It is common to face either drought 
or flooded situation especially in Chhattisgarh. The India Meteorological Department (IMD) forecasts over the broad homogeneous regions, but for any local region like district or division the forecast of IMD doesn't matches in many occasions. There is a correlation between predictors and forecasting of climatic phenomenon can never be perfect. There may also be a cross correlations among predictors and it may suffer epochal changes. It is almost impossible to identify appropriate predictors of climate forecasting over a smaller region like district or division as well. Thus, attempts to forecast climatic phenomenon over a small geographical region like district through this current IMD's operational model become inaccurate. It is furthermore a complicated procedure that includes multiple specialized fields of expertise. Researchers in this field have separated weather forecasting methodologies into two main branches in terms of numerical modeling and scientific processing of meteorological data. The most widespread techniques used for forecasting are the numerical and statistical methods.

Even though researches in these fields are being conducted for a long time, successes of these models are rarely visible. There is limited success in forecasting the weather parameters using the numerical model. The accuracy of the models is dependent upon the initial conditions that are inherently incomplete.

In context of climatology (especially drought) we have gone through an intense survey of 93 major contributions and on that basis, we have made following observations.

\section{LITERATURE REVIEW}

In the last few decades, the weather forecasting has become an important field for research and the various researchers are tried to found the linear relationship between input and targeted data. Abhishek et al., [2], have found that the prediction of the weather for any nonlinear data is irregular trend. However, the discovery of the Artificial Neural Network (ANN) has change the technique to find the structural relationship between the various entities. Further, in the survey, Gurung, [25], has found various ANN approaches for prediction of weather. To find out the complex relationship among factors, the Back Propagation Neural Network (BPN) technique is used by him. The main benefit of the BPN neural network method is that it is more efficient than the numerical differentiation. At the last they have concluded that the above model can apply for forecasting weather in near future in good manner.

After development of ANN based model Krishna, [44], Malik et al., [52], have found that the world's most population, specially the country like India, are depend on the cultivation, where the livelihood of the people are mostly dependent on the monsoon. Further, Baboo and Shereef, [8], Jillella S.S. et al., [35], have also observed that the impact of the monsoon on the livelihood of the Indian families, for prediction of the monsoon rainfall they have applied the Neural Networks package which supports different types of training or learning algorithms on which most useful algorithm is Back Propagation Neural Network (BPN) technique. They have applied Curve fitting and Extrapolation methods with back propagation and found that used model is the most important for prediction of weather.

After the comprehensive study Shrivastava et al., [86], have observed that the Artificial Neural Networks (ANNs) in weather forecasting, especially in rainfall forecasting. They applied the various architectures of ANN such as RBFN, BPN to forecast monsoon rainfall and concluded that the used model is efficient enough to forecast chaotic behavior of weather over the smaller geographical region.

Lu et al., [49], have applied neural network and fuzzy inference system (NFIS-WPM) for weather prediction accurately, further they described that the other models not give the accurate results like above used model. Khajure and Mohod, [39], have used the Back- 
propagation algorithm model for prediction of weather by using various parameters like humidity, temperature, pressure, wind speed etc and concluded the used model gives better result than other models. Nayak, [70], Devi et al., [23], Narvekar and Fargose, [67], have been proposed an ANN based model for prediction of weather parameter like minimum temperature, maximum temperature etc. Since the above model is based on real time data set, on the basis of the above model they have concluded that the used model gives better results than other models.

Mohammed et al., [62], have used the general Artificial Neural Network model to determine the soil temperatures at a range of depths and different measuring times. For identifying the accurate soil surface temperature, the back-propagation algorithm model was used. The result of the used model is successful to estimate and prediction of the soil temperature at different time periods.

Joshi and Ganju, [36], have studied and found that the maximum and minimum temperature is quite helpful for avalanche forecasting and in this regard, they used Artificial Neural Network (ANN) in Western Himalaya region and found that the above model is efficient enough for prediction. Hayati and Mohebi, [27], used the Multi-Layer Perceptron (MLP) for short-term temperature forecasting (STTF) Systems in Kermanshah city, west of Iran, and concluded that the above model gives better results than other models.

Khosravi, [41], has studied about Fuzzy inference nervous system and found that the Sugeno model is appropriate model to predict the minimum and maximum temperature. Further they describe that the used model has two layers one is hidden layer and another is an output layer. Kumar et al., [45], have developed an artificial neural network (ANN) model for prediction of weekly mean temperature. They used various algorithms and found that the back-propagation algorithm is better for weekly temperature prediction.

Rezaei et al., [78], have used the MATLAB software of artificial neural networks for phenomenon and they have found the better results can be achieved by standardizing the data with above model. Further, for prediction of the daily river flow, Kisi, [43] has used various ANN models and concluded that the Auto-Regressive (AR) model gives better result. Akhtar et al., [4], Shamseldin, [85], have applied ANN and (NARXM)-ANN models respectively for river flow forecasting in developing countries and found that the used model gives better result.

Luk et al., [50], have applied the three types of ANNs, namely Multilayer Feed forward Neural Networks, Partial Recurrent Neural Networks and Time Delay Neural Networks for prediction of Rainfall forecasting and found that the ANN gives better result than other models. Khalili et al., [40], have utilized ANN (Artificial Neural Network) modeling with a new approach like three-layer feed-forward perceptron network with back propagation algorithm to predict daily rainfall forecasting. Further they have also described about hidden dynamics of rainfall through the past information of the system and concluded that the used model is best for daily rainfall forecasting. Alfarisy and Mahmudy have, [5], utilized and found Adaptive Neuro Fuzzy Inference System (ANFIS) with hybrid learning method and found that the above model gives high prediction and accurate results for rainfall forecasting.

In the study about weather, Chen et al., [18], have found that the controlling of flood disaster is imperative and for that they have applied the forward back propagation network (FFBP) and conventional regression analysis (CRA) for rainfall prediction and found that the used model is efficient enough. Further, Nayak et al., [68], have found that the behavior of rainfall and climate is highly non-linear and complicated and after their study they have suggested and used the ANN model successfully to predict the behavior of such nonlinear system. In another study, Rathnayake et al., [77], have concluded that the "pressure, 
temperature, dew point, wind direction, wind speed, cloud amount and rainfall" are the important parameters which are used in ANN model for prediction of rainfall efficiently.

In the study of the Landslides, Devi et al., [24], have develops different models to assess landslide occurrence risk based on daily rainfall forecasts and rainfall thresholds and they have found that the ANN model gives better results for landslide occurrence.

Rajurkar et al., [76], Hung et al., [30], have studied about monsoon flood event and suggested that the prediction of rainfall is very helpful for flood disaster management, hence for that they have applied the artificial neural network (ANN) methodology for modeling daily flows during monsoon. Further, the ANN model was used by Hung et al., [29], for forecast rainfall and found that the developed ANN model is efficient enough to predict rainfall.

The Adaptive neuro Fuzzy Inference System (ANFIS) have been developed by Patel and Parekh, [74], for prediction of monthly monsoon rainfall. They have used four evaluation parameters, Root mean-square error (RMSE), Correlation Coefficient (r), Coefficient of Determination (R2) and Discrepancy ratio (D) and found that the ANFIS is best for monsoon rainfall forecast. Rupa and Jain, [80], Kyada and Kumar, [46], have also presented the Adaptive Neuro-fuzzy inference system approach rainfall forecasting and found that the ANFIS is suitable for rainfall forecast.

Pai et al., [72], have studied and developed the ANN model to predict Long range monsoon forecast with selected input parameters namely "sea surface temperature, sea level pressure, humidity, wind speed" and concluded that the used model is accurate for prediction of summer monsoon.

Mekanik et al., [54], have used the feed-forward Artificial Neural Network (ANN) for rainfall forecasting. They have used three different input data sets. The first model investigated the effect of the number of lags on the performance of the ANN. The second model investigated the effect of adding monthly average to the inputs, and the third model considered seasonal average as an extra input data in addition to the ones in the second model. Comparatively they have concluded that the used model performs well for monthly rainfall forecasting. In addition to that Bisht et al., [15], have developed the Artificial Neural Network (ANN) and Support Vector Machine (SVM) and found that, for calculation of average monthly rainfall, used models gives effective results. The ANN model is used by Sahai et al., [81], to prediction of Indian summer monsoon rainfall (ISMR) on a seasonal time scales and found prediction of the used mode is effective. Exploring the new concept, the Root Mean Square Error (RMSE) of ANN model for rainfall, Abbot and Marohasy, [1], have applied and concluded that the RMSE produces the most accurate forecasts compared to other models.

Chiamsathit et al., [19], have used the multi-layer perceptron (MLP) artificial neural networks with the comparison of four inflow situations as, inflow known and assumed to be the historic, forecast, historic mean and with release decision and concluded that MLP gives better result than other models.

In addition to forecast of groundwater level, Nair and Sindhu, [66], Nayak et al., [69], have studied the different combinations of hydrological parameters and identified the factors that influence and control the groundwater level fluctuation and developed an Artificial Neural Networks (ANN) to forecasting the groundwater level and found that the used model is efficient enough to forecast the water levels up to 4 months in advance reasonably well.

In 2016, The Multi-Layer Perceptron (MLP) neural network model has been developed by Hong and Hong, [28], Islam, [33], for forecasting water levels to control flood disaster. Further, Peters et al., [75], have also developed the multilayer feed-forward networks to 
predict flood and they all have found the result that the used model gives accurate result and the result is useful for real-time flood forecasting.

Campolo et al., [16], have found the serious damage and loss from the flood and in this regard, they studied and developed early warning and flood forecasting systems using an Artificial Neural Network. In another research, Toth and Brath, [89], have developed new concept for real-time forecasting of flood and finally they have observed that the above model gives better performance for flood forecasting. Lekkas et al., [48], Subramanian, [87], has also focuses on the implementation of Soft-Computing Technique (Artificial Neural Network) for Flood Management System and found that the of used artificial neural network is best model for flood forecasting.

Shabri, [83], has studied about another nature disaster, named drought, in the world it affects large regions and causing significant damages both in human lives and the natural environment. For, forecasting of Drought, the wavelet and adaptive neuro-fuzzy inference system (WANFIS) was used and found that the performance of WANFIS model is better than other models. Moghadam et al., [59], Woli et al., [93], have found that unlike flood, finding the beginning, duration and ending of drought is so difficult. Further they found that the agricultural reference index for drought (ARID) can be used as a tool to prediction of drought and concluded that the used tool gives the better results.

An Artificial Neural Network (ANN) was developed by Morid et al., [64], to predict quantitative values of drought indices with the Effective Drought Index (EDI) and the Standard Precipitation Index (SPI) models. On the basis of the observation it has been concluded that the performance of the EDI model is more accurate for prediction of drought. Another model of ANN was presented by Dastorani and Afkhami, [21], for prediction of drought in Yazd meteorological station. The architectures of artificial neural networks as well as various combinations of meteorological parameters including 3-year precipitation, they have found that the ANN is an efficient tool to predict drought events.

The standardized precipitation index (SPI) model of ANN for meteorological drought analysis has been applied by Keskin et al., [37], at five stations located around the Lakes District, Turkey and after the analytical performance they have found that the above ANN Model gives best result for drought forecasting. This model has also been applied by Illeperuma and Sonnadara, [32] and concluded that presented Standardized Precipitation Index (SPI) model is accurate for drought prediction. A different tool of ANN, Standardized Precipitation Evapotranspiration Index (SPEI) has been found by Le et al., in 2016, and found the result that prediction can be made with the help of the above ANN Models, [47].

The concept of back propagation artificial neural network (ANN) has been developed and with the experimental basis, Berhanetet al., [14], has concluded that the ANN is the accurate model to forecast drought. A further contribution of Wambua et al., in 2014, have found the result that the Artificial Neural Network is more appropriate for forecasting droughts in Kenya, especially for a typical river basin, [92]. Pai et al., [73], have selected the Standard Percipitation Index for prediction of Drought and flood and they have concluded that the above model is effective for forecast drought and flood.

Mishra and Desai, [56], Bazrafshan et al., [9], Han et al., [26], have proposed, the linear stochastic models known as ARIMA and multiplicative Seasonal Autoregressive Integrated Moving Average (SARIMA) model in the quantitative forecasting of the Standard Runoff Index (SRI) and found that the performance of the above model is efficient enough to predict drought. In the comparatively study between various models of Artificial Neural Network for drought forecast, Jalalkamali et al., 2015, have found that autoregressive integrated moving average (ARIMAX) model gives SPI values and forecast drought with more precision than other models, [34]. 
Memarian et al., [55], have developed the co-active neuro-fuzzy inference system (CANFIS) for drought forecasting and on the basis of the various analysis, they have found that the most accurate model for drought forecasting is CANFIS. For the forecasting of drought, another comparative study has been made by Keskin et al., 2009, between different Adaptive Neural-Based Fuzzy Inference System (ANFIS) and Fuzzy Logic system and finally they have concluded that the ANFIS models gives better result than fuzzy logic models for forecasting drought, [38].

Agana and Homaifar, [3], have developed denoised empirical mode decomposition (EMD) and a deep belief network (DBN) for drought prediction, and on the basis of the different time scale drought indices they concluded that proposed hybrid model showed result in prediction accuracy.

Mishra and Nagarajan, [58], have studied and found the impacts of drought conditions and concluded that the drought is the serious nature disaster. They used recursive feed forward neural network and predicts quantitative values of the Standardized precipitation index (SPI) model for drought forecasting and concluded that the used model is convenient for operational purposes like management of water resources. In addition to that, for prediction of drought, Vali and Roustaei, [90], have proposed Focused Time Delay Neural Networks (FTDNN) model, and on the basis of performance of the above model it was concluded that the proposed model is most efficient for drought prediction.

Moghaddasi et al., [60], Moreira et al., [63], have studied and found that the drought is the destructive climate phenomenon and they developed and used the fuzzy model and developed the function called the Standardized Evapotranspiration and Precipitation Index (SEPI) which is combined form of the Standardized Precipitation Index (SPI) and the Standardized Evapotranspiration Index (SEI). After the utilization of 81 rules in their final fuzzy model, they finally concluded that the above model is efficient for forecasting drought.

In the comparatively study of ANN models, by Belayneh and Adamowski, [12], for the forecasting of drought, they have compared and used Standardized Precipitation Index (SPI), support vector regression (SVR) and coupled wavelet-ANNs and on the basis of input data pre-process they have finally concluded that the coupled wavelet neural network (WA-ANN) models were the most accurate models for forecasting. In another study for forecasting of drought, by Rhee et al., [79], developed a Machine learning-based method and found that the Machine learning-based methods performed better than other models for prediction of droughts.

Aviles et al., [7], have proposed Markov Chain (MC) and Bayesian Network (BN) based models for drought forecasting and used the BNs and the ranked probability skill score (RPSS) to evaluate the performance of the models in copula functions and concluded that the above model provides better forecast of droughts. Ali et al., [6], have used a multilayer perceptron neural network (MLPNN) algorithm for drought forecasting and found that the MLPNN has potential capability for SPEI drought forecasting based on performance measures, like Mean Average Error (MAE), the coefficient of correlation (R), and Root Mean Square Error (RMSE) and finally they have concluded that the above ANN model is very useful for forecasting drought.

Palmer Drought Severity Index (PDSI) model were used by Wambua et al., for spatial and temporal drought variability in the upper Tana River basin with the data for 1970 to 2010, and found that the used ANN model is efficient enough to forecast droughts, [91].

For forecast of drought indices, Maca and Pech, 2016, have used two different models of ANN which were Feed forward Multilayer Perceptron (sANN) and Integrated Neural Network model (hANN). They have used the data for the period of 1948-2002 for analyzed drought indices are the standardized precipitation index (SPI) and the standardized 
precipitation evaporation index (SPEI) and found that the integrated neural network model is superior to other one, [51]. Cancelliere et al., [17], have used Standardized Precipitation Index (SPI) for drought forecasting and concluded that proposed model performed better than other models. In addition to that, the comparative study of Ibrahimi and Baali, [31], they have found that ANFIS model gives SPI values and predictive dryness more accurately than the SVR, and ANN models for drought forecast. Belayneh et al., [11], have proposed and tested the SVR and WA-SVR methods for short term drought forecasting and they have found result that the coupled wavelet neural network (WA-ANN) models are the best models for forecasting drought.

Belayneh and Adamowski, [13] have studied and found that, for the production of effective agriculture, it is necessary to prediction of drought well in advance and for that they have proposed the Data-driven models such as artificial neural networks (ANNs), support vector regression (SVR), and wavelet neural networks (WN) and concluded that the coupled wavelet neural network (WN) models are the best model for forecasting.

Seibert et al., 2015, have worked out to find out the best model for prediction of drought in the Limpopo Basin in southern Africa, and for the said purpose, they have applied and found the result that the ANN model is efficient enough to forecast droughts, [82]. After their work, Moghari and Araghinejad, [61], has also used and presented a new ANN model for prediction of droughts, and found that the developed ANN recursive models performed better than direct models and concluded that the RBF and Generalized Regression Neural Network (GRNN) give best performance in forecasting the drought index and drought class, respectively.

Mossad and Alazba, [65], have selected the ARIMA (Autoregressive Integrated Moving Average) models for drought prediction using the Standardized Precipitation Evapotranspiration Index (SPEI) in a hyper-arid climate and found that the ARIMA models are very useful tools for drought forecasting. Mishra et al., [57], have also proposed the ARIMA and multiplicative Seasonal Autoregressive Integrated Moving Average (SARIMA) models for forecast droughts and finally they have found that the above ANN model is best for forecasting drought.

Ozger et al., 2012, have experimented to perform accurate drought forecasting using wavelet and fuzzy logic (WFL) and developed a combination model and concluded that the WFL model is more accurate than other ANN model for drought forecasting, [71]. After their work, Deo et al., [22], have also developed wavelet-based drought model using extreme learning machine (W-ELM) algorithm and concluded that the W-ELM model is computationally efficient.

Mehr et al., [53], have initially found that to maintain resources of water and drought risk it is necessary to identify the drought in advance, and for that they have used ANN model and developed a new hybrid gene-wavelet model such as wavelet-linear genetic programming (WLGP) for long lead-time drought forecasting and found that the WLGP can be effectively used to forecast drought conditions having 3, 6, and 12-month lead times. In another research by Belayneh et al., 2012, have used machine learning techniques, namely artificial neural network (ANN) and support vector regression (SVR) models for forecasting long-term drought conditions in the Awash River Basin of Ethiopia, and found that the coupled waveletneural network (WANN) and wavelet-support vector regression (WSVR) models were effective models for forecasting drought over long lead times, [10]. After that, Shafaei et al., 2016, have developed the seasonal auto regressive integrated moving average (SARIMA) methods to prediction of drought and finally they have concluded that the wavelet-ANN and wavelet-SARIMA models are accurate for forecasting drought, [84]. Kim and Valdes, [42], have also presented a conjunction model for forecasting of droughts. Further they described 
that, the proposed conjunction model is based on dyadic wavelet transforms and neural networks and finally they have concluded that the conjunction model significantly improves the ability of neural networks for forecasting the indexed regional drought.

In a comparative study of Tan and Perkowski, [88], it was found that the proposed wavelet-coupled machine learning method can effectively predict long-term drought. Choudhary et al., [20], have applied the back propagation artificial neural network for predicting rainfall using maximum and minimum temperature and finally they found the results that the above model is efficient enough for forecasting rainfall.

\section{MAJOR FINIDINGS AND METHODOLOGY USED}

Two main architecture of ANN have been found in the literature review which are sufficient enough to forecast chaotic behaviour of weather like rainfall, temperature, especially Drought and other are discussed in the following subsection:

\subsection{Adaptive Neuro/Neural Fuzzy Inference System (ANFIS)}

For describing the complexity of rainfall, Alfarisy and Mahmudy have, [5], utilized the Adaptive Neuro Fuzzy Inference System (ANFIS) with hybrid learning method and found that the above model gives high prediction and accurate results for rainfall forecasting.

The Adaptive neuro Fuzzy Inference System (ANFIS) have been developed by Patel and Parekh, [74], for prediction of monthly monsoon rainfall. They have used four evaluation parameters, Root mean-square error (RMSE), Correlation Coefficient (r), Coefficient of Determination (R2) and Discrepancy ratio (D) and found that the ANFIS is best for monsoon rainfall forecast.

Pai et al., [72], have developed the ANN model to predict Long range monsoon forecast with input parameters spanning for 36 years (1960-1995) and concluded that the used model is accurate for prediction of summer monsoon.

For prediction of drought wavelet and adaptive neuro-fuzzy inference system (WANFIS) by Shabri, in 2014, and stated that the performance of WANFIS model is better than other models [83].

Lu et al., [49], have utilizes a weather prediction model, based on neural network and fuzzy inference system (NFIS-WPM), which consists of two parts: the first part is the "fuzzy rule based neural network", which simulates sequential relations among fuzzy sets using ANN; and the second part is the "neural fuzzy inference system", which is based on the first part, but could learn new fuzzy rules from the previous ones according to the algorithm.

Rupa and Jain, [80], Kyada and Kumar, [46], have also presented the Adaptive Neurofuzzy inference system approach rainfall forecasting and found that the ANFIS is suitable for rainfall forecast.

After development of fuzzy inference nervous system and genetic algorithm in MATLAB software boxes to predict minimum and maximum temperatures in the city of Khorramabad, Khosravi, [41], has found that for predicting minimum and maximum temperature, the fuzzy neural network and genetic algorithm are accurate models.

Moghadam et al., [59], have presented an Adaptive Neuro-Fuzzy Inference System (ANFIS) for drought forecasting and found that the chosen model is effective for forecasting drought. In the case study of Woli et al., 2013, the agricultural reference index for drought (ARID) tool of ANN model is compared with other approach and concluded that the above model performed better for southern locations in the winter [93].

Memarian et al., [55], have developed the co-active neuro-fuzzy inference system (CANFIS) for drought forecasting and on the basis of the various analyses they have found 
that the most accurate model for drought forecasting is CANFIS. For the forecasting of drought, another comparative study has been made by Keskin et al., 2009, between different Adaptive Neural-Based Fuzzy Inference System (ANFIS) and Fuzzy Logic system and finally they have concluded that the ANFIS models gives better result than fuzzy logic models for forecasting drought, [38].

\subsection{Wavelet and Fuzzy Logic}

Ozger et al., 2012, have experimented to perform accurate drought forecasting using wavelet and fuzzy logic (WFL) and developed a combination model and concluded that the WFL model is more accurate than another ANN model for drought forecasting, [71]. Deo et al., [22], have developed wavelet-based drought model using extreme learning machine (WELM) algorithm and concluded that the W-ELM model is computationally efficient.

Mehr et al., [53], have developed a new hybrid gene-wavelet model such as waveletlinear genetic programming (WLGP) for long lead-time drought forecasting and finally found that the WLGP can be effectively used to forecast drought conditions having 3, 6, and 12month lead times. In another research by Belayneh et al., 2012, have used machine learning techniques, namely artificial neural network (ANN) and support vector regression (SVR) models for forecasting long-term drought conditions in the Awash River Basin of Ethiopia, and found that the coupled wavelet-neural network (WANN) and wavelet-support vector regression (WSVR) models were effective models for forecasting drought over long lead times, [10]. After that, Shafaei et al., 2016, have developed the seasonal auto regressive integrated moving average (SARIMA) methods for drought forecast and finally they have concluded that the wavelet-ANN and wavelet-SARIMA models are accurate for forecasting drought, [84]. Kim and Valdes, [42], have presented a conjunction model for forecast droughts. The proposed conjunction model is based on dyadic wavelet transforms and neural networks. They have finally found the results indicate that the conjunction model significantly improves the ability of neural networks for forecasting the indexed regional drought.

In a comparative study of Tan and Perkowski, [88], it was found that the proposed wavelet-coupled machine learning method can effectively predict long-term drought.

\subsection{Back Propagation Neural Network Methods}

In the survey, Gurung, [25], has observed that the Neural Networks package supports different types of learning or training algorithms. One of the algorithms is Back Propagation Neural Network (BPN) technique which is used by him. Further he described that the main benefit of the BPN neural network method is that it can properly approximate a large class of functions. He has used Real time processing of weather data indicates that the BPN based weather forecast has shown improvement not only over guidance forecasts from numerical models, but over official local weather service forecasts as well. At the last he had concluded that this model has the potential for successful application to forecasting weather in near future.

After development of ANN based model Krishna, [44], Malik et al., [52], have described the dependency on monsoon of world's most population and a great impact on the livelihood of the Indian families where cultivation is a major source of livelihood. Baboo and Shereef, [08], Jillella S.S. et al., [35], have also observed that the Neural Networks package supports different types of training or learning algorithms on which most useful algorithm is Back Propagation Neural Network (BPN) technique. They have applied Curve fitting and Extrapolation methods with back propagation and found that used model is the most important for prediction of weather. 
After the comprehensive study Shrivastava et al., [86], have observed that the Artificial Neural Networks (ANNs) in weather forecasting, especially in rainfall forecasting the architectures of ANN such as BPN, RBFN is best established to be forecast chaotic behaviour and have efficient enough to forecast monsoon rainfall as well as other weather parameter prediction phenomenon over the smaller geographical region.

Devi et al., [23], have found that the Temperature forecasting is the application of science and technology to predict the state of the temperature for a future time at a given location. The Neural Networks package supports different types of training or learning algorithms. One such algorithm is Back Propagation Neural Network (BPN) technique. The main advantage of the BPN neural network method is that it can fairly approximate a large class of functions. This method is more efficient than numerical differentiation. The proposed idea is tested using the real time dataset. Finally, they have compared with practical working of meteorological department and found the results confirm that their model has the potential for successful application to temperature forecasting.

\subsection{Other Methods}

Ali et al. have used a multilayer perceptron neural network (MLPNN) algorithm for drought forecasting. They have applied and tested MLPNN algorithm on monthly time series data of Standardized Precipitation Evapotranspiration Index (SPEI) for various stations and found that the MLPNN has potential capability for SPEI drought forecasting based on performance measures, like Mean Average Error (MAE), the coefficient of correlation (R), and Root Mean Square Error (RMSE). Finally they concluded that the above model is very useful for forecasting drought, [6].

Belayneh and Adamowski, [12], have studied three methods of forecasting short-term drought. They used the Standardized Precipitation Index (SPI) model for forecasting drought index chosen to represent drought. Further they found the following machine learning techniques in the study: artificial neural networks (ANNs), support vector regression (SVR), and coupled wavelet-ANNs, which pre-process input data using wavelet analysis (WA).Finally they found the result that the coupled wavelet neural network (WA-ANN) models were the most accurate models for forecasting.

Rhee et al., 2016, have studied and found that the drought forecasting models are provide high-resolution drought information based on drought indicators for un-gauged areas were developed. The developed models predict drought indices of the 6-month Standardized Precipitation Index (SPI6) and the 6-month Standardized Precipitation Evapotranspiration Index (SPEI6). They have used and compared the three machine learning models such as Decision Tree, Random Forest, and Extremely Randomized and they have finally found the result that the Machine learning-based methods performed better than other models, [79].

Seibert et al., [82], have used Statistical Model for prediction of hydrological droughts during the main runoff period from December to May is assessed; they have used three methods (multiple linear models, artificial neural networks, random forest regression trees) which are compared in terms of their ability to forecast stream flow with up to 12 months of lead time. Finally, they have found the result that the used model is efficient enough to forecast droughts. For forecasting of drought at short-, mid-, and long-term time scales, Moghari and Araghinejad has presented the various neural networks like Recursive MultiStep Multi-Layer Perceptron (RMSMLP), Direct Multi-Step Multi- Layer Perceptron (DMSMLP), Recursive Multi-Step Radial Basis Function (RMSRBF), Direct Multi-Step Radial Basis Function (DMSRBF), Recursive Multi-Step Generalized Regression Neural Network (RMSGRNN), and Direct Multi-Step Generalized Regression Neural Network 
(DMSGRNN) and concluded that the RBF and GRNN give best performance in forecasting the drought, [61].

\section{RESULTS AND DISCUSSION}

After review of a wide range of ANN architecture for drought forecasting, it has been observed that most of the researchers have used different neural network approaches, like ANFIS, WFL and BPN techniques, to forecast nonlinear chaotic data time series. It is practically proved that the neural network techniques have enough potential of pattern recognition problems and it can also predict the future value of the time series. Hence in literature review of 17 years of researches, most of the scientists have found that the artificial neural network is appropriate method to predict weather phenomenon.

\section{CONCLUSION}

An effort to prediction of drought over any smaller geographical region like district or division becomes unsuccessful using statistical models because the correlations fall drastically. It is also difficult to identification of meteorological parameters which are physically connected and effects the prediction of drought. The drought and other climate parameters data behave like chaotic series; thus, it is a challenging task to forecast the internal dynamics of the nonlinear data time series accurately. However, the above study concentrates on ANN capabilities for prediction of several weather phenomenons such as drought, rainfall, flood, temperature etc. After the above survey it has been observed that the models and techniques of ANN are efficient enough for prediction of several weather phenomenon, and finally concluded that the major architectures i.e. ANFIS, BPN, MLP are more suitable and can be efficiently used to predict weather phenomenon.

\section{REFERENCES}

[1] K. Abhishek, M. P. Singh, S. Ghosh, and A. Anand, Weather forecasting model using Artificial Neural Network, Procedia Technology, 2012, 311-318.

[2] A. R. Gurung, Forecasting Weather System Using Artificial Neural Network (ANN): A Survey Paper, International Journal of Latest Engineering Research and Applications, 02(10), 2017, 42-50.

[3] G. V. Krishna, Review of Weather Forecasting Models-Based on Data Mining and Artificial Neural Networks, IJCSC, 6(2), 2015, 214-222.

[4] P. Malik, S. Singh, and B. Arora, An Effective Weather Forecasting Using Neural Network, International Journal of Emerging Engineering Research and Technology, 2(2), 2014, 209-212.

[5] S. S. Baboo, and I. K. Shereef, An Efficient Weather Forecasting System using Artificial Neural Network, International Journal of Environmental Science and Development, 1(4), 2010, 321-326.

[6] S. S. P. R. Jillella, P. B. S. Kiran, P. N. Chowdary, B. R. K. Reddy, and V. Murthy, Weather Forecasting Using Artificial Neural Networks and Data Mining Techniques, International Journal of Innovative Technology And Research, 3(6), 2015, 2534-2539.

[7] G. Shrivastava, S. Karmakar, M. K. Kowar, and P. Guhathakurta, Application of Artificial Neural Networks in Weather Forecasting: A Comprehensive Literature Review, International Journal of Computer Applications, 51(18), 2012, 17-29.

[8] J. Lu, S. Xue, X. Zhang, S. Zhang, and W. Lu, Neural Fuzzy Inference System-Based Weather Prediction Model and Its Precipitation Predicting Experiment, Atmosphere, 5, 2014, 788-805. 
[9] S. R. Khajure, and S. W. Mohod, Prediction of Future Weather Forecasting Using Artificial Neural Network, International Journal of Engineering Research and Applications, 2015, 58-60.

[10] R. Nayak, Artificial Neural Network Model for Weather Predication, International Journal of Applied Information Systems, 2015, 13-16.

[11] C. J. Devi, B. S. P. Reddy, K. V. Kumar, B. M. Reddy, and N. Raja, ANN Approach for Weather Prediction using Back Propagation, International Journal of Engineering Trends and Technology, 3(1), 2012, 19-23.

[12] M. Narvekar, and P. Fargose, Daily Weather Forecasting using Artificial Neural Network, International Journal of Computer Applications, 121(22), 2015, 9-13.

[13] E. M. Mohammed, S. A. Alwahab, and H. A. Warttan, Modeling Soil Temperature Using Artificial Neural Network, $5^{\text {th }}$ International Conference on Environmental Science and Technology, 69(3), 2014, 11-15.

[14] P. Joshi, and A. Ganju, Maximum and minimum temperature prediction over western Himalaya using artificial neural network, MAUSAM, 2, 2012, 283-290.

[15] M. Hayati, Z. and Mohebi, Application of Artificial Neural Networks for Temperature Forecasting, International Journal of Electrical and Computer Engineering, 1(4), 2007, 662-666.

[16] S. Khosravi, Forecasting Temperature using Fuzzy Neural Networks and Genetic Algorithms (Case Study Lorestan Province, Khorramabad City), Int. Journal of Environmental \& Science Education, 11(5), 2016, 993-1006.

[17] P. Kumar, P. S. Kashyap, and J. Ali, Temperature forecasting using artificial neutral networks (ANN), Journal of Hill Agriculture, 4(2), 2013, 110-112.

[18] M. Rezaei, A. A. A. Motlaq, A. R. Mahmouei, and S. H. Mousavi, River Flow Forecasting using artificial neural network, Ciencia e Natura, Santa Maria, 37(1), 2015, 207-215.

[19] O. Kisi, Daily River Flow Forecasting Using Artificial Neural Networks and AutoRegressive Models, Turkish J. Eng. Env. Sci., 29, 2005, 09-20.

[20] M. K. Akhtar, G. A. Corzo, S. J. V. Andel, and A. Jonoski, River flow forecasting with artificial neural networks using satellite observed precipitation pre-processed with flow length and travel time information: case study of the Ganges river basin, Hydrology and Earth System Sciences, 13, 2009, 1607-1618.

[21] A. Y. Shamseldin, Artificial neural network model for river flow forecasting in a developing country, Journal of Hydroinformatics, 2010, 22-35.

[22] K. C. Luk, J. E. Ball, and A. Sharma, An Application of Artificial Neural Networks for Rainfall Forecasting, Mathematical and Computer Modelling, 2001, 683-693.

[23] N. Khalili, S. R. Khodashenas, K. Davary, and F. Karimaldini, Daily Rainfall Forecasting for Mashhad Synoptic Station using Artificial Neural Networks, International Conference on Environmental and Computer Science, 19, 2011, 118-123.

[24] G. A. F. Alfarisy, and W. F. Mahmudy, Rainfall Forecasting in Banyuwangi Using Adaptive Neuro Fuzzy Inference System, Journal of Information Technology and Computer Science, 1(1), 2016, 65-71.

[25] S. M. Chen, Y. M. Wang, and I. Tsou, Using artificial neural network approach for modeling rainfall-runoff due to typhoon, J. Earth Syst. Sci., 2, 2013, 399-405.

[26] D. R. Nayak, A. Mahapatra, and P. Mishra, A Survey on Rainfall Prediction using Artificial Neural Network, International Journal of Computer Applications, 72(16), 2013, 32-40.

[27] V. S. Rathnayake, H. L. Premaratne, and D. U. J. Sonnadara, Performance of neural networks in forecasting short range occurrence of rainfall, Journal of the National Science Foundation of Sri Lanka, 39(3), 2011, 251-260. 
[28] S. R. Devi, P. Agarwal, C. Venkatesh, and P. Arulmozhivarman, Daily Rainfall Forecasting using Artificial Neural Networks for Early Warning of Landslides, International Conference on Advances in Computing, Communications and Informatics, 2014, 2218-2224.

[29] M. P. Rajurkar, U. C. Kothyari, and U. C. Chaube, Artificial neural networks for daily rainfall-runoff modeling, Hydrological Sciences-Journal-des Sciences Hydrologiques, 47(6), 2002, 864-877.

[30] N. Q. Hung, M. S. Babel, S. Weesakul, and N. K. Tripathi, An artificial neural network model for rainfall forecasting in Bangkok, Thailand, Hydrology and Earth System Sciences, 13, 2009, 1413-1425.

[31] N. Q. Hung, M. S. Babel, S. Weesakul, and N. K. Tripathi, An artificial neural network model for rainfall forecasting in Bangkok, Thailand, Hydrology and Earth System Sciences Discussions, 5(1), 2008, 183-218.

[32] J. Patel, and F. Parekh, Forecasting Rainfall Using Adaptive Neuro-Fuzzy Inference System (ANFIS), International Journal of Application or Innovation in Engineering \& Management, 3(6), 2014, 262-269.

[33] Rupa, and S. Jain, Neuro-Fuzzy Based Region Rainfall Forecasting, International Journal of Advanced Research in Computer and Communication Engineering, 4(7), 2015, 161165.

[34] P. M. Kyada, and P. Kumar, Daily Rainfall Forecasting Using Adaptive Neuro-fuzzy Inference System (ANFIS) Models, International Journal of Science and Nature, 6(3), 2015, 382-388.

[35] M. L. Pai, K. V. Pramod, and A. N. Balchand, Long Range Forecast on South West Monsoon Rainfall using Artificial Neural Networks based on Clustering Approach, I. J. Information Technology and Computer Science, 7, 2014, 1-8.

[36] F. Mekanik, T. S. Lee, and M. A. Imteaz, Rainfall modeling using Artificial Neural Network for a mountainous region in West Iran, 19th International Congress on Modeling and Simulation, Perth, Australia, 2011, 3518-3524.

[37] D. Bisht, M. C. Joshi, and A. Mehta, Prediction of Monthly Rainfall of Nainital Region using Artificial Neural Network (ANN) and Support Vector Machine (SVM), IJARIIE, 1(3), 2015, 400-406.

[38] A. K. Sahai, M. K. Soman, and V. Satyan, All India summer monsoon rainfall prediction using an artificial neural network, Climate Dynamics, 16, 2000, 291-302.

[39] J. Abbot, and J. Marohasy, Application of Artificial Neural Networks to Forecasting Monthly Rainfall One Year in Advance for Locations within the Murray Darling Basin, Australia, Int. J. Sus. Dev. Plann, 12(8), 2017, 1282-1298.

[40] C. Chiamsathit, A. J. Adeloye, and S. B. Swamy, Inflow forecasting using Artificial Neural Networks for reservoir operation, International Association of Hydrological Sciences, 2016, 209-214.

[41] S. S. Nair, and G. Sindhu, Groundwater level forecasting using Artificial Neural Network, International Journal of Scientific and Research Publications, 6(1), 2016, 234-238.

[42] P. C. Nayak, Y. R. S. Rao, and K. P. Sudheer, Groundwater Level Forecasting in a Shallow Aquifer Using Artificial Neural Network Approach, Water Resources Management, 20, 2006, 77-90.

[43] J. L. Hong, and K. Hong, Flood Forecasting for Klang River at Kuala Lumpur using Artificial Neural Networks, International Journal of Hybrid Information Technology, 9(3), 2016, 39-60.

[44] A. S. Islam, Improving flood forecasting in Bangladesh using an artificial neural network, Journal of Hydro informatics, 2010, 351-364.

[45] R. Peters, G. Schmitz, and J. Cullmann, Flood routing modeling with Artificial Neural Networks, Advances in Geosciences, 9, 2006, 131-136. 
Application of Neural Network in Drought Forecasting; An Intense Literature Review

[46] M. Campolo, A. Soldati, and P .Andreussi, Artificial neural network approach to flood forecasting in the River Arno, Hydrological Sciences-Journal-des Sciences Hydrologiques, 3(48), 2003, 381-397.

[47] E. Toth, and A. Brath, Flood Forecasting Using Artificial Neural Networks in Black-Box and Conceptual Rainfall-Runoff Modeling, 9th International Congress on Environmental Modeling and Software, 2002, 166-171.

[48] D. F. Lekkas, C. Onof, M. J. Lee, and E. A. Baltas, Application of Artificial Neural Networks for Flood Forecasting, Global Nest: the Int. J., 6(3), 2004, 204-210.

[49] R. Subramanian, Implementation of Neural Networks in Flood Forecasting, International Journal of Scientific and Research Publications, 2(10), 2012, 1-3.

[50] A. Shabri, A Hybrid Wavelet Analysis and Adaptive Neuro-Fuzzy Inference System for Drought Forecasting, Applied Mathematical Sciences, 8(139), 2014, 6909-6918.

[51] M. A. Moghadam, M. Khosravi, H. H. Niknam, and E. J. Nodooshan, Drought Forecasting Using Neuro-Fuzzy Model, Climate Indices and Time Series of Precipitation and Drought Case Study: Zahedan-Iran, Springer, 26, 2012, 17-20.

[52] P. Woli, J. Jones, K. Ingram, and J. Paz, Forecasting Drought Using the Agricultural Reference Index for Drought (ARID): A Case Study, American Meteorological Society, 28, 2013, 427-443.

[53] S. Morid, V. Smakhtin, and K. Bagherzadeh, Drought forecasting using artificial neural networks and time series of drought indices, International Journal of Climatology, 2007, 2103-2111.

[54] M. T. Dastorani, and H. Afkhami, Application of artificial neural networks on drought prediction in Yazd (Central Iran), DESERT, 2011, 39-48.

[55] M. E. Keskin, O. Terzi, E. D. Taylan, and D. Kucukyaman, Meteorological drought analysis using artificial neural networks, Scientific Research and Essays, 6(21), 2011, 4469-4477.

[56] G. Illeperuma, and U. Sonnadara, Forecasting Droughts using Artificial Neural Networks, National Symposium on Disaster Risk Reduction \& Climate Change Adaptation, 2009.

[57] M. H. Le, G. C. Perez, D. Solomatine, and L. B. Nguyen, Meteorological drought forecasting based on climate signals using artificial neural network - a case study in Khanhhoa province Vietnam, Procedia Engineering, 2016, 1169-1175.

[58] G. Berhan, T. Tadesse, and S. Atnafu, Drought Spatial Object Prediction Approach using Artificial Neural Network, Geoinfor Geostat: An Overview, 2015.

[59] R. M. Wambua, B. M. Mutua, and J. M. Raude, Drought Forecasting Using Indices and Artificial Neural Networks for Upper Tana River Basin, Kenya-A Review Concept, J Civil Environ Eng, 4(4), 2014, 1-12.

[60] M. L. Pai, K. V. Pramod, A. N. Balchand, and M. R. R. Kumar, Can the Drought/ Flood Monsoon Conditions over the Indian subcontinent be forecasted using Artificial Neural networks?, Indian Journal of Geo Marine Sciences, 46(04), 2017, 669-677.

[61] A. K. Mishra, and V. R. Desai, Drought forecasting using stochastic models, Stoch Environ Res Risk Assess, 19, 2005, 326-339.

[62] O. Bazrafshan, A. Salajegheh, J. Bazrafshan, M. Mahdavi, and A. F. Marj, Hydrological Drought Forecasting using ARIMA Models (Case Study: Karkheh Basin), ECOPERSIA, 3(3), 2015, 1099-1117.

[63] P. Han, P. Wang, M. Tian, S. Zhang, J. Liu, and D. Zhu, Application of the ARIMA Models in Drought Forecasting Using the Standardized Precipitation Index, HAL Id: hal01348118, https://hal.inria.fr/hal-01348118, 2016.

[64] A. Jalalkamali, M. Moradi, and N. Moradi, Application of several artificial intelligence models and ARIMAX model for forecasting drought using the Standardized Precipitation Index, Int. J. Environ. Sci. Technol., 12, 2015, 1201-1210. 
[65] H. Memarian, M. P. Bilondi, and M. Rezaei, Drought prediction using co-active neurofuzzy inference system, validation, and uncertainty analysis (case study: Birjand, Iran), Springer, 2016, 541-554.

[66] M. E. Keskin, O. Terzi, E. D. Taylan, and D. Kucukyaman, Meteorological drought analysis using data-driven models for the Lakes District, Turkey, Hydrological SciencesJournal-des Sciences Hydrologiques, 6, 2009, 1114-1124.

[67] N. A. Agana, and A. Homaifar, EMD-Based Predictive Deep Belief Network for Time Series Prediction: An Application to Drought Forecasting, Hydrology, 18(5), 2018, 1-20.

[68] S. S. Mishra, and R. Nagarajan, Forecasting Drought in Tel River Basin using Feedforward Recursive Neural Network, International Conference on Environmental, Biomedical and Biotechnology, 41, 2012, 122-126.

[69] A. Vali, and F. Roustaei, An Efficient Approach of Focused Time Delay Neural Network in Drought Forecasting in Central Iran, Journal of Biodiversity and Environmental Sciences, 9(1), 2016, 231-244.

[70] R. Moghaddasi, A. Eghbali, and P. L. Rizi, Analysis and Forecasting of Drought by Developing a Fuzzy-Based Hybrid Index in Iran, Munich Personal Repec Archive, 2014, $1-15$.

[71] E. Moreira, A. Russo, and R. M. Trigo, Monthly Prediction of Drought Classes Using Log-Linear Models under the Influence of NAO for Early-Warning of Drought and Water Management, Water, 10(65), 2018, 1-24.

[72] A. Belayneh, and J. Adamowski, Drought forecasting using new machine learning methods, Journal of Water and Land Development, 6(18), 2013, 3-12.

[73] J. Rhee, J. Im, and S. Park, Drought Forecasting based on Machine Learning of remote sensing and long-range forecast data, The International Archives of the Photogrammetry, Remote Sensing and Spatial Information Sciences, 8, 2016, 157-158.

[74] A. Aviles, R. Celleri, A. Solera, and J. Paredes, Probabilistic Forecasting of Drought Events Using Markov Chain- and Bayesian Network-Based Models: A Case Study of an Andean Regulated River Basin, Water, 2016, 37(8).

[75] Z. Ali, I. Hussain, M. Faisal, H. M. Nazir, T. Hussain, M. Y. Shad, A. M. Shoukry, and S. H. Gani, Forecasting Drought Using Multilayer Perceptron Artificial Neural Network Model, Hindawi-Advances in Meteorology, 2017, 1-9.

[76] R. M. Wambua, B. M. Mutua, and J. M. Raude, Analysis of spatial and temporal drought variability in a tropical river basin using Palmer Drought Severity Index (PDSI), International Journal of Water Resources and Environmental Engineering, 9(8), 2017, 178-190.

[77] P. Maca, and P. Pech, Forecasting SPEI and SPI Drought Indices Using the Integrated Artificial Neural Networks, Computational Intelligence and Neuroscience, 2016, 1-17.

[78] A. Cancelliere, G. D. Mauro, B. Bonaccorso, and G. Rossi, Drought forecasting using the Standardized Precipitation Index, Water Resources Management, 2007.

[79] A. E. Ibrahimi, and A. Baali, Application of Several Artificial Intelligence Models for Forecasting Meteorological Drought Using the Standardized Precipitation Index in the Saiss Plain (Northern Morocco), International Journal of Intelligent Engineering and Systems, 11(1), 2018, 267-375.

[80] A. Belayneh, J. Adamowski, and B. Khalil, Short-term SPI drought forecasting in the Awash River Basin in Ethiopia using wavelet transforms and machine learning methods, Sustain. Water Resource Management, 2, 2016, 87-101.

[81] A. Belayneh, and J. Adamowski, Standard Precipitation Index Drought Forecasting Using Neural Networks, Wavelet Neural Networks, and Support Vector Regression, Applied Computational Intelligence and Soft Computing, 2012, 1-13. 
[82] M. Seibert, B. Merz, and H. Apel, Seasonal forecasting of hydrological drought in the Limpopo Basin: a comparison of statistical methods, Hydrol. Earth Syst. Sci., 21, 2017, 1611-1629.

[83] S. M. H. Moghari, and S. Araghinejad, Monthly and seasonal drought forecasting using statistical neural networks, Environ Earth Sci, 2015.

[84] A. Mossad, and A. A. Alazba, Drought Forecasting Using Stochastic Models in a HyperArid Climate, Atmosphere, 6, 2015, 410-430.

[85] A. K. Mishra, V. R. Desai, and V. P. Singh, Drought Forecasting Using a Hybrid Stochastic and Neural Network Model, Journal of Hydrologic Engineering, 12(6), 2007, 626-638.

[86] M. Ozger, A. K. Mishra, and V. P. Singh, Long Lead Time Drought Forecasting Using a Wavelet and Fuzzy Logic Combination Model: A Case Study in Texas, Journal of Hydrometeorology, 13, 2012, 284-297.

[87] R. C. Deo, M. K. Tiwari, J. F. Adamowski, and J. M. Quilty, Forecasting effective drought index using a wavelet extreme learning machine (W-ELM) model, Stoch Environ Res Risk Assess, 2016.

[88] A. D. Mehr, E. Kahya, and M. Ozger, A gene-wavelet model for long lead time drought forecasting, Journal of Hydrology, 2014, 691-699.

[89] A. Belayneh, J. F. Adamowski, and B. Khalil, Long-term Drought Forecasting Using Wavelet-Neural Networks and Wavelet-Support Vector Regression, American Society of Agricultural and Biological Engineers, 2012.

[90] M. Shafaei, J. Adamowski, A. F. Fard, Y. Dinpashoh, and K. Adamowski, A waveletSARIMA-ANN hybrid model for precipitation forecasting, Journal of Water and Land Development, 28, 2016, 27-36.

[91] T. W. Kim, and J. B. Valdes, A Nonlinear Model for Drought forecasting Based on Conjunction of Wavelet Transforms and Neural Networks, Journal of Hydrologic Engineering, 2003, 1-37.

[92] R. Tan, and M. Perkowski, Wavelet-Coupled Machine Learning Methods for Drought Forecast Utilizing Hybrid Meteorological and Remotely-Sensed Data, Int'l Conf. Data Mining, 2015, 50-56.

[93] P. R. Choudhary, H. Thakur, A. Murade, and M. Venkatesan. Climate Change Prediction Using Artificial Neural Network, International Journal of Applied Engineering Research, 11(3), 2016, 1954-1959. 